\title{
Refining Copper Alloys Carbide Reagents
}

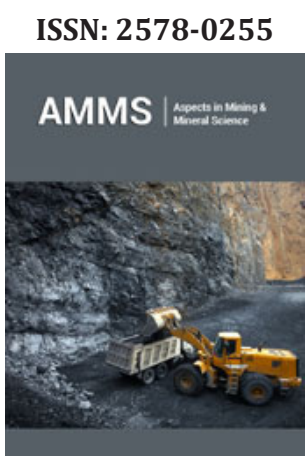

*Corresponding author: Adam W Bydałek, University of Zielona Góra, Faculty of Mechanical Engineering, Department of Metallurgy and Materials Engineering, Poland

\section{Submission: 此 April 23, 2020}

Published: 海 May 04, 2020

Volume 4 - Issue 5

How to cite this article: Adam W Bydałek. Refining Copper Alloys Carbide Reagents. Aspects Min Miner Sci. 4(5). AMMS.000597. 2020.

DOI: 10.31031/AMMS.2020.04.000597

Copyright@ Adam W Bydałek, This article is distributed under the terms of the Creative Commons Attribution 4.0 International License, which permits unrestricted use and redistribution provided that the original author and source are credited.

\section{Adam W Bydałek*}

Faculty of Mechanical Engineering, Department of Metallurgy and Materials Engineering, Poland

\section{Interaction of Slag and Metal}

When considering the Metal-Slag system under equilibrium conditions, it was found that the density of the double electrical layer does not change. This is usually in the form of:

$$
\begin{aligned}
& {[M]-2 e=M^{2+}} \\
& {[O]+2 e=O^{2-}}
\end{aligned}
$$

Which after summary gives;

$$
[M]+[O]=M^{2+} O^{2-}
$$

Reaction (3) can be considered as very simplified under melting conditions in the foundry because:

1) Slag reactions occur simultaneously with the gas environment, e.g. $\left(\mathrm{O}_{2}\right)+4 e=2 \mathrm{O}^{2-}$, which starts the reaction $[M]-2 e=M^{2+}$ and contributes to increasing melting losses,

2) There are constant rearrangements of cations in the slag, both simple and complex (complex) ions.

\section{Analysis of the Copenious Alloy Dexidation Phenomenon in Reducing Conditions of Slag Refining}

Carbon in free state is on the upper surface of the liquid (floats on the surface of the slag) and reacts mainly with oxygen in the gas atmosphere $\left(\mathrm{O}_{2}\right)$ with the effect of creating a $\mathrm{CO} /$ $\mathrm{CO}_{2}$ mixture. Carbides, which have a much higher melting point than copper alloys, occur in metallurgical processes without the use of appropriate solid fluxes. They are almost insoluble in slags and their reactions with the gaseous components of the atmosphere occur on the surfaces of the lumps, which can be written as follows:

$$
\begin{aligned}
& 2<X_{x} C_{y}>+\frac{y+p}{2}\left(O_{2}\right) \rightarrow \frac{x}{z}<X_{z} O_{p}>+y(C O) \\
& \frac{2 z+1}{y}<X_{x} C_{y}>+\left(N_{2}\right) \rightarrow 2 z x\left\{X C N_{2}\right\}+<C>
\end{aligned}
$$

Where: X - carbide forming element.

Based on the research, it was found that the interaction of solid carbides with slags according to reaction No. 4 is very low (about 1-2\%). However, this reaction occurs much more intensively with the participation of nitrogen, especially when the reagent is in a liquid state (formula 5). Under appropriate conditions, carbides are dissolved in slags, occurring in oxygen-carbon and more low-melting joints with nitrogen-oxy-carbon systems. The basic change in this interaction will be dissociation, which can be written as follows:

$$
\left\{X_{x} C_{y}\right\} \rightarrow x\left\{X^{n+}\right\}+y\left\{C^{m-}\right\}
$$

The form of carbon as the $\left\{\mathrm{C}^{\mathrm{m}-}\right\}$ ion should be considered as a conventional form of recording resulting from the configuration of electrons in a carbide compound. After the 
dissociation of carbide, this element, having a structure of $1 \mathrm{~s}^{2} 2$ $\mathrm{s}^{2} 2 \mathrm{p}^{2}$, is transformed into the following ions:

$$
\begin{aligned}
& \left\{C^{-}\right\} \rightarrow\left\{C^{2+}\right\}-3 e \\
& l u b \rightarrow\left\{C^{4+}\right\}-5 e \\
& l u b \rightarrow\left\{C^{+}\right\}-2 e
\end{aligned}
$$

The presence of $\left\{\mathrm{C}^{2+}\right\}$ ions in slag has recently been confirmed in laboratory tests. Adopting the concept of electronic structure of liquid metals, it should be assumed that oxygen forms an interstitial solution in liquid metals. It is believed that oxygen dissolved in the liquid metal does not exist in the atomic form [0] but in the form of the ion $\left[\mathrm{O}^{4+}\right]$, while in the slag in the form of the $\left\{\mathrm{O}^{2-}\right\}$ ion. The transition of oxygen from the liquid metal solution to the slag, based on the interaction of the double electric layer on the surface of the slag-liquid metal phase separation, in addition to overcoming the barriers resulting from surface interactions, requires taking six electrons from the double layer (reaction 10).

$$
\left[\mathrm{O}^{4+}\right]+6 e \rightarrow\left\{\mathrm{O}^{2-}\right\}
$$

So deoxidation of copper and its alloys by carbide slag should be presented in the form of a record:

$$
\begin{aligned}
& {\left[\mathrm{O}^{4+}\right] \rightarrow\left\{\mathrm{O}^{2-}\right\}+6 e+2\left\{\mathrm{C}^{2+}\right\}-6 e \rightarrow(\mathrm{CO})+\left\{\mathrm{C}^{2+}\right\}} \\
& {\left[\mathrm{O}^{4+}\right] \rightarrow\left\{\mathrm{O}^{2-}\right\}+6 e+2\left\{\mathrm{C}^{4+}\right\}-10 e \rightarrow(\mathrm{CO})+\left\{\mathrm{C}^{2+}\right\}-4 e \rightarrow(\mathrm{CO})+<\mathrm{C}>-2 e}
\end{aligned}
$$

Oxygen is also present in the liquid metal as a separate oxide phase $\{\mathrm{MO}$. The transition of such a phase from metal to slag promotes dissociation in solution, which can be expressed in the form of records:

$$
\begin{aligned}
& \{M O\} \rightarrow\left\{M^{2+}\right\}+\left\{O^{2-}\right\}+\left\{C^{2+}\right\}-3 e \rightarrow[M]+\left\{O^{2-}\right\}+\left\{C^{2+}\right\}-1 e \rightarrow[M]+(C O)-1 e \\
& \{M O\} \rightarrow\left\{M^{2+}\right\}+\left\{O^{2-}\right\}+\left\{C^{4+}\right\}-5 e \rightarrow[M]+\left\{O^{2-}\right\}+\left\{C^{4+}\right\}-3 e \\
& i \text { dalej: }[M]+(C O)+\left\{C^{2+}\right\}-3 e \rightarrow[M]+(C O)+<C>-1 e
\end{aligned}
$$

\section{Conclusion}

The problem of deoxidation during the slag refining reduction process was presented. Based on the analysis of the problem and the results of the author's research, it was found that the most promising processes for melting copper alloys are reducing refining conditions. The problem of the interfacial reaction between liquid slag and metal has been interpreted by the electric layer on phase flow (according to the concept of Dietl and Columb). The paper presents an analysis of the slag ion reaction during the refining process with calcium carbide, oxygen, nitrogen and carbon. The author assumed that the ion $\left[\mathrm{O}^{4+}\right]$ in the metal of the form exists, the $\left\{\mathrm{O}^{2-}\right\}$ ion in the slag and shows the most important role of the carbon ions $\left\{\mathrm{C}^{2+}\right\}$ and $\left\{\mathrm{C}^{4+}\right\}$ in the efficiency of the metal extraction process from slag carbide. The balance of deoxidizing copper alloys with carbon and carbide reagents is shown, as well as a scheme of oxygen mass transport through interfacial flow slag-metal. The following symbols were adopted in the work: - giving electrons to the environment, + receiving electrons from the environment. Designation of parentheses: () gaseous state, \{\} substance dissolved in slag, [] substance dissolved in liquid metal, <> solid state. When arranging ionic reaction schemes, the following assumption was made: ion and electron were treated as one complex that is constantly present in slag or metal. 